\title{
Fatores que influenciaram no desempenho de alianças estratégicas firmadas entre empresas do real estate brasileiro
}

\author{
Factors that influence the performance of strategic \\ partnerships between Brazilian real estate companies
}

\section{Cristiane Bueno de Camargo \\ Eliane Monetti \\ Claudio Tavares de Alencar}

\section{Resumo}

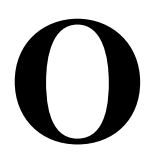

período entre 2006 e 2009 foi caracterizado pela realização de um grande volume de alianças estratégicas entre empresas do real estate brasileiro, cuja estratégia foi adotada por diversas companhias, que, após abertura de capital, traçaram metas agressivas de crescimento. Passados aproximadamente três anos do início dessas parcerias, a partir de meados de 2010, ao dar início à apuração de resultados dos empreendimentos objeto de tais parcerias, as empresas registraram resultados muito abaixo do planejado, em alguns casos resultados negativos. Este artigo tem como objetivo apresentar uma análise diagnóstica dos principais fatores de dificuldade que influenciaram no desempenho de tais parcerias, assim como as principais vantagens identificadas. A pesquisa foi realizada por meio de estudo de caso múltiplo, cujos resultados poderão contribuir para o planejamento de futuras parcerias entre empresas do setor.

Palavras-chaves: Parceria. Aliança estratégica. Estratégia. Diversificação geográfica. Real estate residencial.

\section{Cristiane Bueno de Camargo Universidade de São Paulo São Paulo - SP - Brasil}

Eliane Monetti Universidade de São Paulo São Paulo - SP - Brasil

Claudio Tavares de Alencar Universidade de São Paulo São Paulo - SP - Brasil

Recebido em 04/02/15 Aceito em 27/06/15

\section{Abstract}

The period between 2006 and 2009 was characterised by the establishment of a large number of strategic partnerships between Brazilian real estate companies, whose strategy was adopted by several different firms, which outlined aggressive growth goals after the IPO. About three years after the beginning of these partnerships, from mid-2010, the results of the business ventures produced by the partnerships proved to be much worse than what had been expected, even negative in some cases. This paper aims to present a diagnostic analysis of the main factors that had a negative influence on the performance of such partnerships, as well as the main advantages. The research was conducted through a multiple case study, whose analysis can contribute to the planning of future partnerships between companies in the Brazilian real estate business.

Keywords: Partnership. Strategic partnerships. Strategy. Geographic diversification. Residential real estate. 


\section{Introdução}

O ambiente competitivo da globalização tem exigido cada vez mais o "desenvolvimento de perspectivas, capacidades e infraestrutura [...] em velocidade que poucas empresas conseguem dominar" (DOZ; HAMEL, 2000, p. 9-10). A adoção de alianças estratégicas se apresenta como uma alternativa relevante, por possibilitar que as empresas unam esforços e partilhem conhecimento, podendo oferecer o que têm de melhor em sua estrutura, permitindo evitar "esforços lentos e dispendiosos para a formação de capacidades" (DOZ; HAMEL, 2000), aumentando as possibilidades de absorver as oportunidades apresentadas pelo mercado.

A adoção de alianças estratégicas no setor do real estate não é fato recente. No entanto, entre 2006 e 2009, observou-se um aumento expressivo no volume de tais alianças, tanto horizontais - entre empresas do mesmo nível da cadeia produtiva quanto verticais - empresas de diferentes níveis dessa cadeia. Tal aumento justifica-se principalmente por dois fatores:

(a) a intensificação da atividade imobiliária a partir do final de 2005, fomentada pelas perspectivas positivas do cenário macroeconômico contemplando a redução das taxas de juros, aumento da oferta de crédito, a flexibilização para obtenção de financiamentos para pessoas físicas e jurídicas, além da adoção de políticas públicas de incentivo ao setor; $\mathrm{e}$

(b) realização de "IPO" por 22 empresas do setor, que, capitalizadas, traçaram estratégias agressivas de crescimento.

Conforme Alencar (2012), além de demonstrar capacidade de geração de receita, tais empresas se depararam com a obrigação de remunerar os recursos captados em padrões de rentabilidade similares aos alcançados na fase anterior à abertura de capital. Tal obrigatoriedade exigiu delas revisões estratégicas que contemplaram:

(a) formação de landbank $k^{2}$ : sob a ótica do mercado de capitais "deter propriedades" poderia representar "deter receita futura";

(b) diversificação de segmento de produto, estando a maior demanda por produtos residenciais alocada no público de baixa renda; e

(c) diversificação geográfica, tendo em vista o potencial de crescimento apresentado por mercados em cidades brasileiras fora do eixo RioSão Paulo.

${ }^{1}$ Sigla em inglês para oferta pública de ações.

${ }^{2}$ Banco de terrenos.
Conforme Souza (2011), de 2006 a 2010, 86 parcerias horizontais foram firmadas entre empresas de capital aberto e empresas com atuação em âmbito local, sendo 12 joint ventures, 16 aquisições e 3 fusões. Considerando o modelo de parceria - acordos operacionais em nível de empresa, sem aporte de recursos, ou coincorporação por meio de participação na Sociedade de Propósito Específico (SPE) do empreendimento, 9 visavam à expansão para segmentos de menor renda, 9 objetivavam a ampliação de oportunidades nos mercados tradicionais e 67 tinham o objetivo de entrar em novas regiões geográficas. Apenas uma declarou o objetivo de acessar novas regiões e segmentos de renda simultaneamente.

A partir de meados de 2010, verificou-se um período de "acomodação", caracterizado pela consolidação de três tipos de empresas:

(a) as muito grandes, que mantiveram a estratégia de diversificação, dando continuidade ao processo de aquisição e parcerias com empresas menores;

(b) as médias, que mantiveram, de forma mais moderada relativamente às grandes, a estratégia de diversificação, porém sem ações relevantes de expansão; e

(c) empresas menores, que, apesar de terem capital aberto, atuam com foco em cada projeto (ALENCAR, 2012).

Concluído o ciclo de parte dos empreendimentos objeto das parcerias, os balanços referentes ao exercício de 2010 registraram queda de desempenho por parte dessas companhias, ainda que outras empresas tenham apresentado crescimento expressivo do lucro líquido em relação ao ano anterior.

Tal queda de desempenho tornou-se mais abrangente e intensa em 2011 e 2012, quando diversas companhias registraram prejuízos representativos. Tais resultados foram atribuídos principalmente ao rápido e intenso crescimento das operações, associado ao planejamento inadequado "desse crescimento". Observou-se, a partir de 2011, a revisão da estratégia de grande parte das empresas que passaram por essas experiências, contemplando dissoluções de parcerias em andamento, a priorização do desenvolvimento de novos empreendimentos contando apenas com suas próprias estruturas e a retomada do foco para seus mercados e segmento de produto de origem.

Ante o exposto e considerando a relevância das alianças estratégicas para o crescimento e/ou o monitoramento da competitividade no ambiente 
corporativo atual, a presente pesquisa tem como objetivo identificar os fatores de dificuldade que influenciaram no desempenho delas, assim como suas principais vantagens.

Tais informações visam a contribuir em reflexões para o planejamento de futuras parcerias, objetivando potencializar suas vantagens e mitigar dificuldades que possam comprometer seu desempenho.

\section{Método de pesquisa}

Devido ao caráter qualitativo das informações levantadas e por se tratar de aspectos da contemporaneidade, optou-se pela utilização do método de estudo de caso, o qual se trata de "[...] uma investigação empírica que busca compreender um fenômeno contemporâneo em profundidade e em seu contexto de vida real [...]" (YIN, 2010, p. 39).

Adotou-se o método de estudos de caso múltiplos, sendo selecionadas cinco empresas de capital aberto, doravante denominadas EPs, atuantes predominantemente nas cidades de São Paulo e Rio de Janeiro, as quais, após abertura de capital, firmaram alianças estratégicas com empresas de atuação local em cidades do Norte e Nordeste brasileiro, visando à expansão geográfica. A escolha do Norte e do Nordeste justifica-se pela representatividade do volume de parcerias estabelecidas nessas regiões em relação ao restante do país. Objetivando averiguar a convergência das informações, realizaram-se também entrevistas com duas empresas locais, denominadas ELs, parceiras das EPs, e com duas empresas de consultoria, denominadas ECs, que estiveram envolvidas diretamente nas parcerias.

As entrevistas foram realizadas por meio de questionário semiestruturado, tendo sido elaborado um modelo para cada grupo de empresas supracitado. Nas EPs foram entrevistados tanto profissionais atuantes na diretoria quanto no nível gerencial. Nas ELs e ECs foram entrevistados profissionais da diretoria. Parte das entrevistas foi realizada presencialmente, e parte respondida via e-mail e complementada por contato telefônico, o que não comprometeu a qualidade e a fidelidade das informações coletadas.

Visando a verificar a convergência das informações e a ratificar os dados primários, foram também levantados dados secundários, extraídos de artigos acadêmicos, entre os quais artigos relacionados aos aspectos que motivaram parcerias entre empresas do real estate no início do período em que ocorreu grande volume de parcerias e a influência da estratégia empresarial sobre o desempenho dessas empresas. Levantou-se também dados de periódicos, revistas setoriais e websites contendo notícias sobre as ações de empresas do setor no período em questão, sobre lançamentos de produtos e sobre o desempenho dos empreendimentos e das organizações. Parte dos dados secundários, por dispor de informações relacionadas a empreendimentos e experiências específicas, auxiliou na compreensão de alguns aspectos relatados de forma mais genérica pelos entrevistados, a partir da confrontação e associação desses dados.

Restringiu-se ao estudo de alianças feitas entre 2006 e 2010 devido ao volume de parcerias realizadas entre empresas do setor nesse período. Limitou-se também ao estudo de alianças realizadas sob o modelo de parcerias, considerando a representatividade desse modelo diante do volume de alianças.

Para a compilação dos dados aplicou-se o método de redução do texto original apresentado por Flick (2004), por meio de codificação temática. Para tanto, apoiando-se nos conceitos extraídos da revisão bibliográfica, realizou-se a análise dos dados da primeira entrevista e buscou-se extrair a essência dos relatos inerentes aos objetivos, dificuldades e vantagens, relacionado-as a uma palavra ou expressão "chave", ou seja, um "tema". A partir dos temas preestabelecidos, buscou-se enquadrar os dados das demais entrevistas aos referidos "temas", criando-se assim tal agrupamento. Ao longo da análise dos dados, foram acrescidos outros temas.

\section{Revisão bibliográfica}

Entre a diversidade de definições apresentadas na literatura para o termo "alianças estratégicas", pode-se afirmar que são relações formais criadas com a finalidade de buscar conjuntamente metas mútuas. Cada organização compartilha a autoridade administrativa, forma relações sociais e aceita a propriedade conjunta (BATEMAN; SNELL, 2007). Por meio de alianças as empresas podem selecionar, desenvolver e empregar capacidades essenciais, preenchendo lacunas de capacidade, de forma a obter vantagem competitiva, aumentar o valor ao cliente e direcionar mercados, renovando continuamente suas posições (HARBISON; PEKAR JUNIOR, 1999).

Harbison e Pekar Junior (1999) caracterizam as alianças como:

(a) transacionais: relações estabelecidas geralmente por meio de contratos, em que não se compartilham capacidades fundamentais, o 
relacionamento não envolve controle e os parceiros não dispõem de uma estratégia conjunta; e

(b) alianças estratégicas: caminho intermediário entre alianças transacionais e aquisições; baseiamse em participação ou compartilhamento de capacidades e em uma relação recíproca com estratégias compartilhadas.

Para Barney e Hesterly (2011) as alianças podem ser classificadas nas seguintes categorias:

(a) "sem participação acionária": cooperação administrada por meio de contratos, sem a realização de investimento uma na outra, tampouco a criação de uma empresa independente;

(b) "com participação acionária": os contratos são suplementados por investimentos de uma empresa na outra, havendo situações em que tais investimentos são recíprocos; e

(c) "joint-ventures": se constitui uma entidade legalmente independente, com a realização de investimentos por parte das empresas envolvidas.

Entre fatores que podem motivar a constituição de alianças estratégicas estão: economias de escala, aprendizado com os competidores, proteção contra riscos financeiros e compartilhamento de investimentos, facilidade de cooperação tácita, entrada em novos mercados e indústrias com baixo investimento e gestão de incertezas (BARNEY; HESTERLY, 2011), a necessidade de se enfrentar um "inimigo comum", condições adversas de negócios ou "poder combinado de outras alianças" (LEWIS; 1992).

Se, por um lado, as alianças estratégicas permitem a transformação de concorrentes em potenciais aliados, a criação de valor diferenciado a recursos, a aprendizagem e a internalização de novas habilidades, evitando-se esforços lentos e dispendiosos para a formação de capacidades (DOZ; HAMEL, 2000), por outro lado apresentam complexidade e dificuldade de gestão. A gestão vitoriosa de uma aliança requer comprometimento e envolvimento profundo dos envolvidos, nos diversos níveis hierárquicos, além de reflexões aprofundadas acerca de suas vantagens, desvantagens e dificuldades para embasar a decisão de constituir a aliança.

\section{Vantagens e desvantagens das alianças estratégicas}

A condução de alianças é mais trabalhosa do que relações menos intensas, de forma que a contribuição que trarão à organização, considerando oportunidades, custos, serviços, qualidade, novos desenvolvimentos, volume e velocidade de crescimento, melhor compreensão de mercado, são fatores relevantes a ser avaliados ante o trabalho demandado (LEWIS, 1992).

No Quadro 1 apresentam-se as principais vantagens e desvantagens das alianças estratégicas (BARROS, 2001).

\section{Fatores de conflito e de sucesso}

A forma pela qual o valor é criado para cada organização envolvida em uma aliança não é predeterminado, o que gera incertezas, ambiguidade e consequentes dificuldades no relacionamento, sendo a administração dessa relação fator essencial para o desempenho dela (BARROS, 2001). Assim sendo, apontam-se alguns aspectos que podem elevar a possibilidade de êxito das alianças.

Quadro 1 - Vantagens e desvantagens das alianças

\begin{tabular}{|c|c|c|}
\hline & Vantagens & Desvantagens \\
\hline $\begin{array}{l}\text { - Alianças } \\
\text { Estratégicas }\end{array}$ & $\begin{array}{l}\text { - Acesso a oportunidades por meio de } \\
\text { complementaridade e sinergias } \\
\text { - Compartilhamento de recursos } \\
\text { - Flexibilidade para adaptação a mudanças } \\
\text { - Maior força diante de terceiros que não } \\
\text { cumprem responsabilidades contratuais } \\
\text { - Menor custo de transação. Compra e venda de } \\
\text { produtos e serviços entre empresas } \\
\text { comprometidas com a aliança } \\
\text { - Alto potencial de aprendizagem } \\
\text { - Redução ou compartilhamento de riscos }\end{array}$ & $\begin{array}{l}\text { - } \\
\text { Elevada probabilidade de } \\
\text { incompatibilidades culturais } \\
\text { - Riscos de conflitos entre os } \\
\text { parceiros abrangendo a } \\
\text { definição dos objetivos } \\
\text { estratégicos da aliança. } \\
\text { Aspectos econômicos e } \\
\text { operacionais } \\
\text { - Controle parcial da operação }\end{array}$ \\
\hline
\end{tabular}

Fonte: adaptado de Barros (2001, p. 93). 
Para a fase de formação destaca-se a importância de um planejamento criterioso, para o qual Harbison e Pekar Junior (1999) apresentam um conjunto de práticas adotadas por empresas que obtiveram bom desempenho em suas parcerias. Tais práticas contemplam a preparação de um estudo embasado em informações consistentes, que retratem com a maior fidelidade possível as condições do ambiente de atuação; a prevenção de riscos de negócios analisando o efeito da aliança sobre a competitividade da empresa-mãe; a interligação dos orçamentos aos recursos e prioridades; a condução de um processo criterioso de seleção de parceiros; o planejamento de recursos, determinando a contribuição de cada parceiro; e o estabelecimento de medidas de desempenho e pacotes de compensação que reflitam a natureza do projeto.

Considerando que as parcerias entre empresas do real state, em sua maioria, objetivam a realização de empreendimentos imobiliários, Lima Junior (2009) menciona algumas questões que devem ser respondidas por empresas incorporadoras ao se planejar uma operação, conforme o Quadro 2.

Destaca-se também a importância de um processo adequado de seleção de parceiros que deve envolver análises quanto à compatibilidade da cultura dos envolvidos (BRONDER; PRITZI, 1992) e análises associadas à personalidade do empresário parceiro (GERINGER, 1991). Para
Brouthers, Brouhers e Wilkinson (1995) uma aliança só deve ser constituída se houver entre os parceiros a complementaridade de capacidades, a probabilidade de cooperação cultural mútua e aprendizado recíproco, a compatibilidade de objetivos, não somente para a aliança, mas para as empresas individualmente, e a possibilidade de se mensurarem os riscos.

Doz e Hamel (2000) destacam que, entre um plano de aliança estrategicamente forte e bem projetado e o êxito de sua implementação há uma série de hiatos que podem separar parceiros potencias e com estratégias complementares e que precisam ser transpostos.

O Quadro 3 contempla os principais hiatos apresentados por Doz e Hamel (2000) e suas prováveis origens.

Harbison e Pekar Junior (1999) também destacam práticas adotadas por empresas que obtiveram êxito em suas alianças, entre as quais estão a criação de uma estrutura organizacional flexível e enxuta, com processos baseados nas estratégias e requisitos da aliança, e não nos requisitos dos parceiros; o acompanhamento da reação dos concorrentes e o estabelecimento de ferramentas que permitam o acompanhamento e a avaliação periódicos da evolução da aliança, assim como as revisões necessárias por meio de canal de comunicação aberto entre as partes, que assegure flexibilidade na resolução das questões.

Quadro 2 - Questões a serem respondidas no planejamento de parcerias no setor do real state

\begin{tabular}{|c|c|}
\hline \multicolumn{2}{|c|}{ QUESTÕES A SEREM RESPONDIDAS NO PLANEJAMENTO DE PARCERIAS } \\
\hline \multirow[b]{2}{*}{$\begin{array}{l}\text { DECISÕES } \\
\text { ESTRATÉGICAS }\end{array}$} & $\begin{array}{l}\text { Plano de metas } \\
\stackrel{\leftrightarrow}{\Rightarrow} \text { Está definida a equação de meios: equação de fundos, equipes, sistemas, } \\
\quad \text { equipamentos, logística, outros? }\end{array}$ \\
\hline & $\begin{array}{l}\text { Dispersão entre mercados } \\
\text { (aplicável à realização de parcerias que objetivam a diversificação geográfica) } \\
\stackrel{\Leftrightarrow}{\Leftrightarrow} \text { A estrutura de gestão implantada é adequada? } \\
\stackrel{\leftrightarrow}{\Leftrightarrow} \text { A dispersão da decisão está bem resolvida? } \\
\stackrel{\leftrightarrow}{\Rightarrow} \text { A intensificação dos controles, função dessa dispersão está implementada? }\end{array}$ \\
\hline \multicolumn{2}{|c|}{ QUESTÕES A SEREM RESPONDIDAS NO PLANEJAMENTO DE PARCERIAS } \\
\hline \multirow[b]{2}{*}{$\begin{array}{l}\text { DECISÕES } \\
\text { TÁTICAS }\end{array}$} & $\begin{array}{l}\text { Busca de oportunidades de investimento e sua hierarquização } \\
\stackrel{\leftrightarrow}{\Leftrightarrow} \text { Os métodos de análise são revestidos da qualidade técnica adequada? }\end{array}$ \\
\hline & $\begin{array}{l}\text { Validação e escolha de empreendimentos } \\
\Leftrightarrow \text { A rotina de validação transmite segurança? } \\
\Leftrightarrow \text { A decisão a distância pode estar sujeita à manipulação? } \\
\Leftrightarrow \text { A rotina de validação envolve capacidade de fazer ou somente atratividade } \\
\text { do investimento? }\end{array}$ \\
\hline $\begin{array}{l}\text { NÍVEL } \\
\text { OPERACIONAL }\end{array}$ & 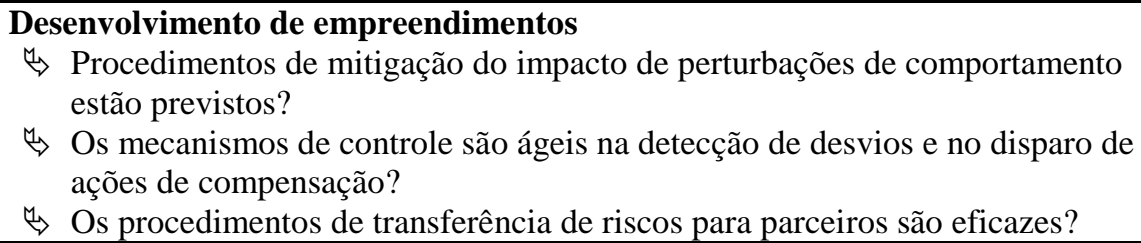 \\
\hline
\end{tabular}


Fonte: adaptado de Lima Junior (2009, p. 4).

Quadro 3 - Principais hiatos entre parceiros

\begin{tabular}{|c|c|c|}
\hline \multicolumn{3}{|c|}{$\begin{array}{l}\text { PRINCIPAIS HIATOS INERENTES AO CONTEXTO DA ALIANÇA E DAS } \\
\text { ORGANIZAÇÕES }\end{array}$} \\
\hline $\begin{array}{c}\text { Tipos de } \\
\text { Hiato }\end{array}$ & Importância & Prováveis Origens \\
\hline $\begin{array}{l}\text { Hiato de } \\
\text { Referenciais }\end{array}$ & $\begin{array}{l}\text { - Para a compreensão dos } \\
\text { relacionamentos, regras e } \\
\text { perspectivas, motivando a interação } \\
\text { do dia a dia. }\end{array}$ & $\begin{array}{l}\text { - Referenciais equivocados, baseados em } \\
\text { outras formas de cooperação, } \\
\text { experiências anteriores ou diferentes } \\
\text { estruturas } \\
\text { - Mesma natureza, porém estrutura e } \\
\text { referenciais diferentes } \\
\text { - Referenciais diferentes dentro da } \\
\text { mesma empresa } \\
\text { - Referenciais obsoletos }\end{array}$ \\
\hline $\begin{array}{l}\text { Hiato de } \\
\text { Expectativas }\end{array}$ & $\begin{array}{l}\text { - "Benchmark" para comparação com o } \\
\text { desempenho efetivo, ou identificação } \\
\text { de sinais de alerta referentes a } \\
\text { dificuldades de desempenho }\end{array}$ & $\begin{array}{l}\text { - O processo de negociação pode levar a } \\
\text { expectativas excessivamente otimistas } \\
\text { - Superestimativa da contribuição das } \\
\text { partes }\end{array}$ \\
\hline \multicolumn{3}{|c|}{ PRINCIPAIS HIATOS INERENTES AOS PROCESSOS } \\
\hline Tipos de Hiato & Importância & Prováveis Origens \\
\hline $\begin{array}{l}\text { Hiato de } \\
\text { Contexto } \\
\text { Organizacional }\end{array}$ & $\begin{array}{l}\text { - Compatibilidade entre parceiros na } \\
\text { estrutura, processo decisório, } \\
\text { trabalho e aprendizagem }\end{array}$ & $\begin{array}{l}\text { - Disparidade no porte e no estilo } \\
\text { organizacionais dificulta o } \\
\text { compartilhamento de referenciais e } \\
\text { expectativas } \\
\text { - Diferenças na gestão do conhecimento } \\
\text { e processo decisório impedem a } \\
\text { tomada de decisões conjuntamente } \\
\text { - Estabelecimento de rotinas } \\
\text { organizacionais próprias } \\
\end{array}$ \\
\hline $\begin{array}{l}\text { Hiato de } \\
\text { Confiança }\end{array}$ & $\begin{array}{l}\text { - A autoconfiança permite fortes } \\
\text { compromissos pessoais e assunção } \\
\text { de riscos pessoais na cooperação; a } \\
\text { falta de confiança dificulta a } \\
\text { cooperação plena }\end{array}$ & $\begin{array}{l}\text { - Medo de perder prestígio, em função } \\
\text { da aliança ou dentro da aliança } \\
\text { - Medo de perder influência e cargo } \\
\text { - Ameaça quando a coespecialização é } \\
\text { desfavorável } \\
\text { - Resistência em submeter-se à } \\
\text { dependência mútua }\end{array}$ \\
\hline $\begin{array}{l}\text { Hiato de } \\
\text { Compreensão } \\
\text { das } \\
\text { Habilidades }\end{array}$ & $\begin{array}{l}\text { - Necessidade de combinar habilidades } \\
\text { diferenciadas entre parceiros, } \\
\text { principalmente onde for necessária a } \\
\text { integração de processos }\end{array}$ & $\begin{array}{l}\text { Habilidades diferenciadas e } \\
\text { distanciadas - dificuldade de conexão } \\
\text { das habilidades } \\
\text { - Habilidades refletidas em "modos" } \\
\text { organizacionais diferentes - } \\
\text { dificuldade de conexão entre parceiros } \\
\text { - Integração e interface } \\
\end{array}$ \\
\hline $\begin{array}{l}\text { Hiato de } \\
\text { Definição de } \\
\text { Tarefas }\end{array}$ & $\begin{array}{l}\text { Necessidade de definir um conjunto } \\
\text { concreto de tarefas para iniciar a } \\
\text { cooperação operacional e tangível }\end{array}$ & $\begin{array}{l}\text { - Imprecisão na definição de tarefas } \\
\text { - Necessidade de revisar escopo das } \\
\text { tarefas }\end{array}$ \\
\hline
\end{tabular}

Fonte: adaptado de Doz e Hamel (2000, p. 158-159).

Considerando as características do real state, Lima Junior (2009) chama a atenção para a importância da qualidade das análises da qualidade do investimento (AQIs) para a validação do negócio e do estabelecimento de processos rigorosos de planejamento e controle dos empreendimentos objeto das parcerias, cujos resultados estão ligados ao desempenho da parceria. 


\section{Apresentação dos estudos de caso}

Os resultados são apresentados destacando-se os relatos das EPs, das ELs e das ECs, explicitando a visão de cada uma das partes acerca dos temas abordados. Visando a preservar a identidade das empresas entrevistadas, elas são referenciadas por letras, e a ordem adotada não representa uma hierarquização.

\section{Características das empresas entrevistadas}

Todas as EPs entrevistadas são empresas incorporadoras e construtoras de grande representatividade no setor, tendo quatro delas mais de 30 anos de atividade e uma delas entre 10 e 20 anos. Antes da diversificação geográfica atuavam principalmente no eixo Rio-São Paulo, predominantemente nas capitais, e após a abertura de capital passaram a atuar em diversas regiões brasileiras.

As ELs encontravam-se no período pré-parcerias entre as três primeiras de sua região de atuação. Atuam com maior foco na incorporação e construção de empreendimentos residenciais de médio e alto padrão, além de empreendimentos comerciais. Uma delas atua também com produtos residenciais do segmento econômico, porém com menor foco.

Entre as ECs, uma delas tem larga experiência em consultoria nas áreas técnica, tecnológica e de gestão, abrangendo todas as etapas do ciclo de empreendimentos imobiliários. A segunda empresa é especializada em assessoria financeira para processos de parcerias, "joint ventures", fusões e aquisições.

\section{Características das parcerias realizadas}

As parcerias foram constituídas inicialmente visando à realização de um empreendimento específico. Em diversos casos, posteriormente foram estendidas a novos empreendimentos. A formalização de tais parcerias se deu por meio de memorandos de entendimentos, cujo instrumento jurídico dispunha das diretrizes da parceria e regulava a forma de participação das partes nas SPEs. As participações por parte das EPs variavam entre $30 \%$ e $50 \%$.
Algumas parcerias foram constituídas a partir de terrenos previamente adquiridos pelas ELs, e outras contemplaram a aquisição conjunta do terreno.

O principal objetivo das parcerias por parte das EPs é a diversificação geográfica, a qual decorre de objetivos estratégicos específicos, como o crescimento das operações e a elevação da competitividade em curto espaço de tempo, de forma a atender aos compromissos estabelecidos mediante a abertura de capital. As ELs, por sua vez, diante da intensificação das atividades setoriais e da intenção de grandes incorporadoras em se estabelecer em novos mercados, vislumbraram a possibilidade de realização de parcerias em duas situações:

(a) "oportunidade" de crescimento da operação decorrente de novas fontes de recursos para estruturação de "funding" e ampliação do volume na prestação de serviços de construção, no caso das empresas construtoras; e

(b) "condição" para estabelecer um padrão de competitividade tendo em vista a ação das grandes incorporadoras para se estabelecer em suas regiões de atuação.

Além dos objetivos individuais das organizações, o desempenho das parcerias está vinculado aos objetivos da "parceria em si". O quadro que se segue apresenta os principais objetivos que motivaram a constituição de tais alianças, classificados em:

(a) objetivos globais e individuais das organizações;

(b) objetivos específicos que motivaram a adoção das parcerias como estratégia para se alcançarem os objetivos estratégicos globais: "fatores críticos de sucesso";

(c) objetivos das alianças: resultados que se pretendem alcançar conjuntamente por meio da aliança; e

(d) objetivos das organizações a partir dos resultados da aliança.

A divisão de responsabilidades entre as organizações se deu conforme as competências e know-how que cada parte dispunha para contribuir com a parceria, sendo que, em sua maioria, as ELs ficaram responsáveis por atividades operacionais que demandavam conhecimento do mercado local, e as EPs responsáveis pelo gerenciamento financeiro. As decisões estratégicas eram compartilhadas entre as partes. 
Quadro 4 - Objetivos estratégicos das organizações e das alianças

\begin{tabular}{|c|c|c|c|c|}
\hline \multicolumn{5}{|c|}{ Objetivos estratégicos das organizações versus objetivos das alianças } \\
\hline & \multicolumn{2}{|c|}{ Objetivos Estratégicos da Organização } & \multirow[b]{2}{*}{ Objetivos da aliança } & \multirow{2}{*}{$\begin{array}{c}\text { Objetivos das } \\
\text { organizações a partir } \\
\text { dos resultados da } \\
\text { aliança }\end{array}$} \\
\hline & $\begin{array}{c}\text { Objetivos } \\
\text { globais }\end{array}$ & $\begin{array}{c}\text { *Objetivos que motivaram a } \\
\text { adoção de parcerias } \\
\text { (FATORES CRÍTICOS) } \\
\end{array}$ & & \\
\hline $\mathbf{E P}$ & $\begin{array}{l}\text { - Crescimento } \\
\text { da operação } \\
\text { em curto } \\
\text { prazo } \\
\text { - Elevação de } \\
\text { participação } \\
\text { no mercado }\end{array}$ & $\begin{array}{l}\text { APRENDIZADO } \\
\text { - Economia de tempo e } \\
\text { investimento em } \\
\text { aprendizado para inserção } \\
\text { em novo mercado } \\
\text { - Velocidade na geração de } \\
\text { novos negócios por meio da } \\
\text { expertise do parceiro local } \\
\text { - Assertividade na } \\
\text { estruturação de produtos } \\
\text { embasada no conhecimento } \\
\text { da cultura local por parte do } \\
\text { parceiro } \\
\text { - Flexibilidade para a } \\
\text { realização de negócios } \\
\text { pontuais }\end{array}$ & \multirow{2}{*}{$\begin{array}{l}\text { - Realização de um ou } \\
\text { mais } \\
\text { empreendimentos } \\
\text { imobiliários } \\
\text { - Velocidade na } \\
\text { estruturação e no } \\
\text { lançamento de novos } \\
\text { negócios imobiliários }\end{array}$} & $\begin{array}{l}\text { - Velocidade na } \\
\text { apropriação de } \\
\text { resultados } \\
\text { - Preferência por } \\
\text { velocidade de vendas } \\
\text { em detrimento de } \\
\text { preservação do preço } \\
\text { de vendas } \\
\text { - Interesse na } \\
\text { intensificação de } \\
\text { investimentos para } \\
\text { imprimir velocidade } \\
\text { na produção e } \\
\text { conclusão de obras }\end{array}$ \\
\hline $\mathbf{E L}$ & $\begin{array}{l}\text { - Crescimento } \\
\text { da operação } \\
\text { por meio de } \\
\text { acesso a } \\
\text { novas fontes } \\
\text { de funding } \\
\text { - Manutenção } \\
\text { da } \\
\text { competitivi- } \\
\text { dade }\end{array}$ & $\begin{array}{l}\text { APRENDIZADO } \\
\text { - Obtenção de novos } \\
\text { conhecimentos técnicos, } \\
\text { tecnológicos e de gestão } \\
\text { - Crescimento e maior } \\
\text { participação no mercado } \\
\text { NEUTRALIZAÇÃO DE } \\
\text { CONCORRENTES } \\
\text { - Realização de } \\
\text { empreendimentos de maior } \\
\text { escala } \\
\text { - Administração da } \\
\text { competitividade } \\
\text { - Estruturação de funding } \\
\text { para novos } \\
\text { empreendimentos } \\
\text { - Melhores condições de } \\
\text { financiamento à produção }\end{array}$ & & $\begin{array}{l}\text { - Preferência pela } \\
\text { preservação do preço } \\
\text { de vendas } \\
\text { - Preservação da } \\
\text { margem de resultados } \\
\text { - Preservação do } \\
\text { cronograma/limitações } \\
\text { para intensificação de } \\
\text { investimentos }\end{array}$ \\
\hline
\end{tabular}

Nota: * objetivos estratégicos que determinaram a adoção da aliança.

Identificaram-se ao longo das parcerias ajustes na divisão de responsabilidades, em que ELs assumiram determinadas responsabilidades inicialmente atribuídas às EPs, tendo em vista seu potencial de contribuição para tal atividade. Além de alterações na divisão de responsabilidades, em casos em que as empresas parceiras dispunham de diversos empreendimentos em conjunto, devido à elevação do volume, houve revisões na distribuição da gestão, passando as EPs a gerir diretamente parte dos empreendimentos.

Independentemente da divisão de responsabilidades, verificaram-se diferentes formas de operacionalizar o acompanhamento dos empreendimentos in loco. Determinadas empresas compuseram estruturas regionais, mantendo profissionais técnicos in loco para acompanhamento dos empreendimentos. Com a elevação do volume de empreendimentos e parcerias, algumas EPs dispuseram de uma equipe compacta de profissionais administrativos responsáveis pela controladoria. Outras organizações optaram por manter membros de sua equipe, como gerentes e coordenadores, de 2 a 3 dias semanais atuando na base da empresa local. Houve ainda situação em que a EP não dispunha de profissionais in loco, tendo, porém, contratado uma gerenciadora para o acompanhamento da 
construção. Nesses casos, após a identificação de desvios, a EP mudou a estratégia, alocando profissionais próprios na região e, por fim, montando uma estrutura regional.

Não se constataram, no entanto, diferenças significativas entre as dificuldades relatadas pelas EPs associadas ao tipo de gestão adotada. Houve, porém, a percepção de que, excetuando-se as divergências culturais, a presença de profissionais das EPs in loco agilizou tomadas de decisão conjuntas.

Quanto à autonomia para a condução dos processos de compras e contratações, observou-se a predominância de atribuição de autonomia parcial para as ELs, com liberdade para contratações até um limite de valor acordado. Contratações cujos valores excedessem tal limite deveriam ser autorizadas pelas EPs.

\section{Principais fatores que influenciaram no desempenho das parcerias}

\section{Alinhamento de objetivos estratégicos}

No que se refere ao objetivo fundamental das parcerias, que é o crescimento das operações e a manutenção e/ou elevação da competitividade em curto período, o que se viabilizaria por meio da troca de competências e absorção de conhecimentos específicos do parceiro, verificouse o alinhamento entre as empresas parceiras. Esse aspecto fica evidente nas respostas apresentadas nas entrevistas e é ratificado por dados extraídos de notícias publicadas por revistas setoriais e veículos de comunicação digital acerca das parcerias realizadas no período pós-abertura de capital por parte de grandes companhias do setor.

Apesar do alinhamento no que se refere ao objetivo fundamental, observou-se certo desequilíbrio de interesses no fator gerador do interesse pelas parcerias. Enquanto as EPs buscavam uma oportunidade de crescimento, as ELs assumiam uma postura de proteção de sua posição no mercado. Tal constatação não anula, no entanto, o alinhamento de objetivos no que se refere à troca de competências e recursos para obtenção de rápido crescimento das operações.

Quanto aos resultados dos empreendimentos observaram-se divergências entre os objetivos individuais de EPs e ELs, decorrentes de fatores relacionados aos objetivos estratégicos globais de cada organização, tais como a flexibilidade quanto a ajustes nas margens de resultados dos empreendimentos, flexibilidade para variações significativas no fluxo de investimentos e representatividade de cada empreendimento na "carteira de empreendimentos" das empresas envolvidas. Tais aspectos são abordados de forma detalhada adiante, ao se discutirem as dificuldades das parcerias.

\section{Análise do ambiente de atuação}

Algumas das dificuldades identificadas durante a condução das alianças resultaram de pouco aprofundamento das consequências do "movimento coletivo" das grandes incorporadoras em direção a mercados menos explorados.

Ao se vislumbrarem oportunidades de investimento e crescimento em regiões que apresentavam demandas reprimidas e maior disponibilidade de terrenos para incorporação, avaliou-se o comportamento do mercado considerando a atuação das empresas locais. Não se atribuiu a devida atenção às prováveis mudanças decorrentes da futura ação de diversas grandes empresas que também passariam a atuar nessas regiões, gerando crescimento da oferta, da competitividade, e impactando na velocidade de vendas dos produtos e respectivos resultados e rentabilidade.

A intensificação das atividades setoriais verificada na época trouxe também consequências como a escassez de mão de obra, de equipamentos e de insumos, repercutindo nas operações do setor, conforme mencionado no Quadro 6. Publicações realizadas no período em questão por revistas setoriais e voltadas à macroeconomia vão ao encontro das afirmações extraídas dos dados primários.

As prováveis origens das dificuldades acima apresentadas foram elaboradas com base nos contextos relatados nas entrevistas e na análise dos dados secundários acerca das ações adotadas por empresas do setor no período em questão. Diversas publicações relacionadas a aspectos de planejamento foram realizadas tanto no período de aquecimento das atividades quanto no período de retração o setor.

\section{Fatores relacionados ao desenvolvimento e condução das parcerias}

Analisando os fatores que refletiram no desempenho das parcerias verificaram-se dificuldades que têm correspondência com o conceito dos "hiatos" apresentado por Doz e Hamel (2000). Identificou-se ainda um hiato adicional, o qual se denominou "hiato de estrutura organizacional", associado às diferenças de disponibilidade de recursos financeiros, de necessidades de mudanças táticas e estratégicas e de necessidades de prestação de contas dos resultados. 
Quadro 5 - Dificuldades relacionadas ao ambiente de atuação

\begin{tabular}{|c|c|}
\hline \multicolumn{2}{|c|}{ Dificuldades relacionadas ao ambiente de atuação e contexto em que se firmaram as parcerias } \\
\hline Dificuldades identificadas nos estudos de caso & $\begin{array}{c}\text { Prováveis origens }{ }^{2} \\
\text { (autor do presente trabalho) }\end{array}$ \\
\hline $\begin{array}{l}\text { Estrutural } \\
\text { - Inexperiência de gestores. Diversos gestores ainda não haviam } \\
\text { vivenciado "um ciclo completo" de empreendimentos do real state } \\
\text { - Distância geográfica e infraestrutura de comunicação ineficaz em } \\
\text { algumas regiões }\end{array}$ & - \\
\hline $\begin{array}{l}\text { Gestão (prazos, custos e qualidade) } \\
\text { - Despreparo das ELs para intensificação abrupta do volume de } \\
\text { produção } \\
\text { - Despreparo das EPs para absorver o gerenciamento de elevada } \\
\text { quantidade de empreendimentos no "back office" } \\
\text { - Despreparo das EPs para o modelo de gestão implementado, com } \\
\text { empreendimentos "pulverizados" por regiões distintas }\end{array}$ & $\begin{array}{l}\text { - Previsões subestimadas das demandas } \\
\text { que seriam geradas pelas parcerias e } \\
\text { aumento do volume de produção } \\
\text { - Priorização do planejamento } \\
\text { estratégico global individual - } \\
\text { crescimento da operação para } \\
\text { absorção das oportunidades } \\
\text { decorrentes do cenário } \\
\text { macroeconômico e setorial }^{2}\end{array}$ \\
\hline
\end{tabular}

Quadro 6 - Relação entre dificuldades de natureza cultural e hiatos

\begin{tabular}{|c|c|c|}
\hline \multicolumn{3}{|c|}{ Dificuldades de natureza cultural } \\
\hline Tipo de hiato & Dificuldades identificadas nos estudos de caso & $\begin{array}{c}\text { Prováveis origens das dificuldades } \\
\text { (DOZ; HAMEL, 2000) } \\
\text { 2(autor do presente trabalho) } \\
\end{array}$ \\
\hline $\begin{array}{l}\text { Hiato de } \\
\text { compreensão } \\
\text { das } \\
\text { habilidades }\end{array}$ & $\begin{array}{l}\text { - Gerenciamento das relações entre as diferentes } \\
\text { culturas }\end{array}$ & $\begin{array}{l}\text { - Habilidades refletidas em "modos" } \\
\text { organizacionais diferentes - } \\
\text { dificuldade de conexão entre } \\
\text { parceiros }{ }^{1}\end{array}$ \\
\hline \multirow{2}{*}{$\begin{array}{l}\text { Hiato de } \\
\text { confiança }\end{array}$} & - Resistência na absorção do know-how das ELs & $\begin{array}{l}\text { - Insegurança em “delegar” decisões; } \\
\text { excesso de confiança na própria } \\
\text { experiência }^{2}\end{array}$ \\
\hline & $\begin{array}{l}\text { - Tendência de proteção da cultura e identidade } \\
\text { empresarial; "imposição" do conhecimento } \\
\text { próprio }\end{array}$ & $\begin{array}{l}\text { - Preocupação com a imagem da } \\
\text { organização }\end{array}$ \\
\hline
\end{tabular}

Visando a estabelecer uma reflexão mais aprofundada dos resultados, relacionaram-se os referidos hiatos às dificuldades apontadas e às prováveis origens com base na revisão bibliográfica. As prováveis origens apontadas resultam de uma reflexão embasada no cruzamento dos dados primários e secundários da pesquisa com os conceitos apresentados na literatura, sendo que os contextos descritos na pesquisa, ratificados pelos dados secundários, levam ao entendimento de que tais aspectos provavelmente originaram tais dificuldades ou influenciaram em sua origem, somando-se a outros fatores não explicitados nos resultados obtidos.

Para facilitar a reflexão, agruparam-se as dificuldades da seguinte forma: dificuldades de natureza cultural (regionalismo), dificuldades inerentes ao planejamento estratégico e dificuldades de natureza operacional, conforme o Quadro 6 ao Quadro 8.
O fator "diferença cultural" foi repetidamente apontado e relacionado a diferenças no modo de gerir e operacionalizar os negócios. Tal relação leva ao entendimento de que essas dificuldades podem estar mais ligadas à falta de compreensão da operação do parceiro do que à cultura em si, podendo gerar insegurança quanto aos resultados que ele pode proporcionar à parceria. Portanto, ações no sentido de compreender os diferentes modus operandi devem ser tomadas antes de se estabelecerem barreiras de conexão entre as partes.

A preocupação com a preservação da imagem das organizações ficou evidente nos resultados da pesquisa ao se verificar que a seleção dos parceiros teve como uma das premissas a busca por empresas reconhecidas e bem colocadas em seu ambiente de atuação. Por outro lado, o fato de as EPs deterem maior experiência na realização de empreendimentos de grandes volumes influenciou na forma como delegavam atividades e decisões, levando ao entendimento de que a resistência na

64 Camargo, C. B. de; Monetti, E.; Alencar, C. T. de. 
absorção do know-how dos parceiros esteve associada à maior confiança na própria experiência e na falta de conhecimento nos processos dos parceiros.

Diferenças relacionadas à necessidade de apresentação de resultados exigiram ações no sentido de intensificar a velocidade de vendas ou ainda a velocidade de produção. Tais ajustes envolvem política de vendas e ações de marketing e elevação dos investimentos respectivamente, podendo impactar em alterações no resultado dos empreendimentos e, consequentemente, no desempenho das parcerias. EPs e ELs não dispunham da mesma flexibilidade para absorver as consequências de tais ajustes estratégicos.

\section{Quadro 7 - Relação entre dificuldades de planejamento estratégico e hiatos}

\begin{tabular}{|c|c|c|}
\hline \multicolumn{3}{|c|}{ Dificuldades relacionadas ao planejamento estratégico } \\
\hline Tipo de hiato & Dificuldades identificadas nos estudos de caso & $\begin{array}{c}\text { Prováveis origens } \\
{ }^{1}(\mathrm{DOZ} ; \text { HAMEL, 2000) } \\
{ }^{2} \text { (autor do presente trabalho) } \\
\end{array}$ \\
\hline Hiato de tempo & 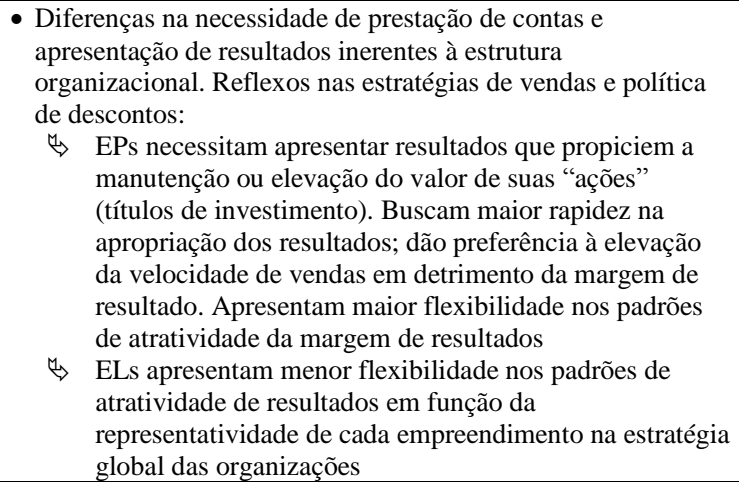 & $\begin{array}{l}\text { - Divergência de expectativas quanto a fluxo } \\
\text { de investimentos e prazos para a obtenção } \\
\text { dos benefícios }{ }^{1}\end{array}$ \\
\hline $\begin{array}{c}\text { Hiato de tempo } \\
+ \\
\text { Hiato de } \\
\text { expectativas } \\
+ \\
\text { Hiato de } \\
\text { estrutura } \\
\text { organizacional }\end{array}$ & $\begin{array}{l}\text { - Diferenças de expectativas quanto ao volume de produção: } \\
\text { EPs intencionam intensificar investimentos, e ELs têm } \\
\text { limitações inerentes à estrutura }\end{array}$ & $\begin{array}{l}\text { - Diferença de prazos para a obtenção dos } \\
\text { resultados }{ }^{1} \\
\text { - Objetivos estratégicos individuais não } \\
\text { analisados com profundidade na fase de } \\
\text { formalização, dificultando a compreensão } \\
\text { das expectativas das partes }{ }^{2} \\
\text { - Capacidade de investimentos; } \\
\text { disponibilidade de recursos } \\
\end{array}$ \\
\hline $\begin{array}{c}\text { Hiato de contexto } \\
\text { organizacional } \\
+ \\
\text { Hiato de } \\
\text { estrutura } \\
\text { organizacional } \\
\end{array}$ & $\begin{array}{l}\text { - Diferença na capacidade de realizar mudanças de estratégia na } \\
\text { implantação dos empreendimentos devido à representatividade } \\
\text { de cada negócio na carteira de empreendimentos das } \\
\text { empresas. ELs têm menor flexibilidade para mudanças. EPs } \\
\text { interrompem investimentos onde se torna menos atrativo }\end{array}$ & $\begin{array}{l}\text { - Disparidade no porte e estilo } \\
\text { organizacionais }{ }^{1} \\
\text { - Diferença na proporção de ajustes táticos } \\
\text { e/ou estratégicos demandados para atender } \\
\text { às necessidades globais das organizações, } \\
\text { inerentes ao porte delas }{ }^{2}\end{array}$ \\
\hline Tipo de hiato & Dificuldades identificadas nos estudos de caso & $\begin{array}{c}\text { Prováveis origens } \\
{ }^{1}(\text { DOZ; HAMEL, 2000) } \\
{ }^{2} \text { (autor do presente trabalho) } \\
\end{array}$ \\
\hline \multirow{2}{*}{$\begin{array}{c}\text { Hiato de contexto } \\
\text { organizacional }\end{array}$} & $\begin{array}{l}\text { Estruturação de novos negócios } \\
\text { - Condução das negociações de terrenos e elaboração de } \\
\text { contratos somente por ELs, sem a participação das EPs. } \\
\text { Necessidades de eventuais ajustes posteriores para atender a } \\
\text { padrões e necessidades das EPs } \\
\text { - Redução da velocidade de aquisição de terrenos decorrente } \\
\text { dos processos de validação das EPs - aprovações em comitês }\end{array}$ & $\begin{array}{l}\text { - Estabelecimento de rotinas organizacionais } \\
\text { próprias }^{1} \\
\text { - Diferenças entre os ritmos tácitos e } \\
\text { explícitos de tomada de decisões impedem } \\
\text { [ou dificultam] tomadas de decisões } \\
\text { conjuntamente }^{1}\end{array}$ \\
\hline & $\begin{array}{l}\text { Estruturação de novos negócios } \\
\text { - Diferenças de expectativas e de padrões de atratividade para } \\
\text { os indicadores da qualidade } \\
\text { - Divergência de parâmetros para a composição de cenários } \\
\text { para as análises da qualidade do investimento e diferença de } \\
\text { padrões de atratividade }\end{array}$ & $\begin{array}{l}\text { - Diferenças inerentes ao porte das } \\
\text { organizações e necessidades de geração de } \\
\text { resultados } \\
\text { - Diferença de estilos: estilos intuitivos e } \\
\text { analíticos dificultam o compartilhamento } \\
\text { de referenciais e expectativas } \\
\text { - Diferença de disponibilidade para absorção } \\
\text { de riscos }\end{array}$ \\
\hline
\end{tabular}


Quadro 8 - Relação entre dificuldades de natureza operacional e hiatos

\begin{tabular}{|c|c|c|}
\hline \multicolumn{3}{|c|}{ Dificuldades de natureza operacional } \\
\hline $\begin{array}{c}\text { Tipo de hiato } \\
\text { (DOZ; HAMEL, } \\
\text { 2000) }\end{array}$ & Dificuldades identificadas nos estudos de caso & $\begin{array}{c}\text { Prováveis origens } \\
\text { 1(DOZ; HAMEL, 2000) } \\
\text { 2(autor do presente trabalho) }\end{array}$ \\
\hline $\begin{array}{l}\text { Hiato de } \\
\text { estrutura } \\
\text { organizacional }\end{array}$ & $\begin{array}{l}\text { Estrutural } \\
\text { - Dedicação dos gestores compartilhada com diferentes } \\
\text { bases: alterações de foco dos gestores, por haver } \\
\text { regiões que lhe demandavam maior atenção } \\
\text { - Gestão de diversas parcerias por parte das EPs. } \\
\text { Necessidade de atendimento a diversos parceiros em } \\
\text { regiões distintas, resultando em mudança de foco em } \\
\text { determinadas "praças" } \\
\text { - Diferenças no rigor de controles de custos e prazos } \\
\text { devido à inexperiência da organização }\end{array}$ & $\begin{array}{l}\text { - Diferença de foco diante do objetivo } \\
\text { global das organizações }\end{array}$ \\
\hline \multicolumn{3}{|c|}{$\begin{array}{c}\text { Dificuldades de natureza operacional } \\
\end{array}$} \\
\hline $\begin{array}{c}\text { Tipo de hiato } \\
\text { (DOZ; HAMEL, } \\
\text { 2000) } \\
\end{array}$ & Dificuldades identificadas nos estudos de caso & $\begin{array}{c}\text { Prováveis origens } \\
\text { 1(DOZ; HAMEL, 2000) } \\
\text { 2(autor do presente trabalho) }\end{array}$ \\
\hline $\begin{array}{l}\text { Hiato de } \\
\text { contexto } \\
\text { organizacional } \\
+ \\
\text { Hiato de } \\
\text { estrutura } \\
\text { organizacional }\end{array}$ & \begin{tabular}{|l} 
Estrutural \\
- Dificuldade no estabelecimento das relações \\
hierárquicas entre as equipes em decorrência da \\
diferença de estrutura organizacional \\
- Divergência de cultura empresarial dificultando a troca \\
de informações entre equipes \\
- Dificuldade em regular relação de equilíbrio, \\
decorrente da diferença significativa do porte das \\
empresas parceiras - tal dificuldade gerou mais \\
implicações do que as diferenças de cultura regional \\
- Morosidade de decisões decorrentes de: \\
$\Leftrightarrow$ incompatibilidade de prazos e conteúdos na troca de \\
informações; \\
$\Leftrightarrow$ distância geográfica; \\
$\Leftrightarrow$ dependência de aprovações das duas organizações - \\
EP tinha menor velocidade em função de sua \\
estrutura, refletindo na velocidade da EL; \\
$\Leftrightarrow$ dependência de aprovações em muitos níveis \\
hierárquicos devido à estrutura da EP
\end{tabular} & $\begin{array}{l}\text { - Estabelecimento de rotinas } \\
\text { organizacionais próprias }{ }^{1} \\
\text { - Diferenças na gestão do } \\
\text { conhecimento entre os ritmos tácitos e } \\
\text { explícitos de tomada de decisões }{ }^{1} \\
\text { - Disparidade no porte e no estilo } \\
\text { organizacionais dificulta o } \\
\text { compartilhamento de referenciais e } \\
\text { expectativas }{ }^{1} \\
\text { - Diferença no porte da organização } \\
\text { refletindo em capacidade, } \\
\text { expectativas quanto a fluxos de } \\
\text { investimento, obtenção dos retornos e } \\
\text { necessidade de prestação de contas }{ }^{2} \\
\text { - Planejamento de gestão a distância } \\
\text { baseado em referenciais de } \\
\text { experiências do mercado de origem de } \\
\text { atuação }\end{array}$ \\
\hline $\begin{array}{l}\text { Hiato de } \\
\text { compreensão } \\
\text { das habilidades }\end{array}$ & $\begin{array}{l}\text { Estrutural } \\
\text { - Dificuldade de aceitação das práticas do mercado local: } \\
\text { gestores com conhecimento consolidado em gestão, } \\
\text { porém pouco familiarizados com o ambiente do real } \\
\text { state local; preferência por replicar experiências } \\
\text { próprias } \\
\text { - Diferença de rotinas e/ou ausência de procedimentos e } \\
\text { rotinas de análise de crédito, gestão de contratos e } \\
\text { repasse à instituição financeira }\end{array}$ & $\begin{array}{l}\text { - Estabelecimento de rotinas } \\
\text { organizacionais próprias }{ }^{1} \\
\text { - Habilidades refletidas em "modos" } \\
\text { organizacionais diferentes - } \\
\text { dificuldade de conexão entre } \\
\text { parceiros" }\end{array}$ \\
\hline $\begin{array}{l}\text { Hiato de } \\
\text { compreensão } \\
\text { das habilidades } \\
+ \\
\text { Hiato de } \\
\text { referenciais }\end{array}$ & $\begin{array}{l}\text { Gestão (prazos, custos e qualidade) } \\
\text { - Característica da mão de obra local: mais generalista, } \\
\text { que atua em diversas fases do processo produtivo. } \\
\text { MDO do Sudeste é especializada e direcionada para as } \\
\text { etapas específicas de produção } \\
\text { - Diferenças na forma de alocação dos recursos humanos } \\
\text { em obras, resultando em conflitos no planejamento da } \\
\text { produção; diferenças nos padrões de produtividade } \\
\text { inerentes diferenças culturais } \\
\text { - Expectativas das EPs quanto ao trabalho de prestadores } \\
\text { de serviços locais } \\
\text { - Centralização de atendimento ao cliente em São Paulo }\end{array}$ & $\begin{array}{l}\text { - Estabelecimento de rotinas } \\
\text { organizacionais próprias }{ }^{1} \\
\text { - Habilidades refletidas em "modos" } \\
\text { organizacionais diferentes - } \\
\text { dificuldade de conexão entre } \\
\text { parceiros }{ }^{1} \\
\text { - Referenciais baseados em } \\
\text { experiências obtidas no mercado de } \\
\text { origem }^{2}\end{array}$ \\
\hline $\begin{array}{l}\text { Hiato de } \\
\text { contexto } \\
\text { organizacional }\end{array}$ & $\begin{array}{l}\text { Gestão (prazos, custos e qualidade) } \\
\text { - Incompatibilidade entre sistemas gerenciais: dificultou } \\
\text { troca de informações iniciais }\end{array}$ & \\
\hline
\end{tabular}

66 Camargo, C. B. de; Monetti, E.; Alencar, C. T. de. 
Ao se analisar o contexto das dificuldades relatadas, verifica-se que parte das dificuldades esteve associada à insuficiência de entendimento quanto aos objetivos individuais dos parceiros, sua capacidade e disponibilidade para absorção de riscos e sua flexibilidade para ajustes. As entrevistas evidenciam que tais aspectos não foram avaliados na fase que precedeu a constituição das parcerias e que não houve planejamento efetivo para a implementação delas. Dados secundários publicados no período em que começaram a se apurar os resultados das parcerias ratificam tais constatações.

O aumento substancial das operações foi uma dificuldade vivenciada tanto por ELs como por EPs. Para as EPs tal dificuldade esteve associada à necessidade de adequações de processos gerenciais e operacionais. Entende-se que no primeiro momento vislumbrou-se a possibilidade de acelerar o crescimento por meio das parcerias, considerando que a estrutura dos parceiros supriria o "crescimento de estrutura" demandado pela ampliação das atividades. "Multiplicar" a estrutura por meio das parcerias, no entanto, não seria o bastante. Seria necessária a adequação de processos, cujas necessidades receberam maior atenção quando as operações já haviam se multiplicado. Daí uma das principais origens das dificuldades relatadas: o despreparo para conduzir o crescimento nas proporções e prazos em que ocorreram. Ter-se baseado nas experiências obtidas nos mercados de origem também refletiu em dificuldades tais como a gestão a distância e a adaptação do planejamento da produção.

Além das dificuldades citadas, as ELs apresentavam limitação quanto à disponibilidade de recursos financeiros, cuja dificuldade tornou-se mais representativa à medida que impossibilitava a convergência de interesses, conforme discutido anteriormente.

Particularidades da mão de obra local foram apontadas como dificuldades devido a sua influência nos prazos demandados para a implantação dos empreendimentos. Nesse sentido, destaca-se a importância de se contemplarem "regionalismos" no planejamento da parceria e respectivos empreendimentos, além de dispor de flexibilidade para adaptações.

\section{Principais vantagens}

As principais vantagens apontadas pelas EPs foram a velocidade na geração de novos negócios e a inserção em novos mercados em decorrência da expertise das ELs. Tais vantagens evidenciam o alcance dos objetivos caracterizados como "fatores críticos de sucesso", ou seja, a velocidade de crescimento das operações por meio da expansão geográfica e a "economia de tempo de aprendizado" sobre novos mercados por meio da troca de competências.

Também correspondentes aos referidos objetivos, as EPs citaram como vantagens o acesso às oportunidades de negociações de terrenos em condições vantajosas, devido ao conhecimento de mercado e à rede de relacionamento dos profissionais locais, o poder de negociação com fornecedores e a contribuição das ELs com sua expertise para a definição dos produtos e para o aprendizado sobre o mercado.

As ELs, por sua vez, apresentaram como principais vantagens a possibilidade de realização de empreendimentos de maiores proporções e volume, os quais não poderiam realizar sozinhas, a abertura de canais de relacionamento e trabalho com grandes agentes do mercado tanto na incorporação em si quanto em projetos, e marketing e vendas, que contribuíram para o aprendizado e amadurecimento dos processos na organização. De forma mais específica, foi citado como vantagem o amadurecimento dos processos de gestão e governança, tais como o planejamento e acompanhamento da evolução dos empreendimentos e elaboração de relatórios gerenciais. Tais apontamentos também demonstram o alcance dos objetivos de aprendizado e o crescimento das operações.

Verifica-se, portanto, que, independentemente das dificuldades relatadas, os objetivos caracterizados como "fatores críticos de sucesso" que motivaram a realização das parcerias foram, em sua maioria, alcançados pelas organizações envolvidas.

\section{Considerações finais}

A presente pesquisa teve como objetivo a identificação das principais dificuldades e fatores que impactaram no desempenho das parcerias realizadas entre empresas do real state no período entre 2006 e 2009 visando a induzir reflexões que possam contribuir no planejamento de futuras parcerias entre empresas do setor.

Verificou-se no início da parceria o alinhamento de objetivos das organizações no que se refere ao crescimento das operações e elevação/manutenção da competitividade por meio da troca de competências, sendo divergências de interesses inerentes à diferença de estrutura organizacional constatadas ao longo das parcerias, influenciando em decisões estratégicas que impactavam nos resultados dos empreendimentos, da parceria e das organizações individualmente. 
As analogias realizadas permitiram identificar que parte das dificuldades associadas pelos respondentes às diferenças culturais está mais relacionada a aspectos de planejamento do que a aspectos culturais em si. Verificou-se que, devido à velocidade com que as parcerias foram firmadas, não houve um planejamento com o rigor necessário que contemplasse avaliação criteriosa do parceiro, seu modelo de operação, capacidade de crescimento para atender ao novo volume que seria gerado com as parcerias, prazos e custos necessários para eventuais adaptações operacionais e crescimento da estrutura, prazos e custos para adequações de sistemas gerenciais e infraestrutura visando à compatibilidade entre as organizações e, principalmente, o planejamento relacionado às expectativas e à capacidade de investimento das partes.

Analisando a relação entre os hiatos e as dificuldades de planejamento estratégico, verificase que, em sua maioria, são implícitas à diferença de porte das organizações, o que era inerente ao próprio modelo das parcerias em questão ante os objetivos traçados e o ambiente em que foram constituídas. Considerando que não há flexibilidade para adequações em aspectos estruturais das organizações, entende-se que maior atenção deve ser dada às "prováveis origens dos hiatos" ao se planejarem as parcerias.

As dificuldades de natureza operacional ratificam a importância de se considerarem no planejamento das parcerias avaliações quanto à necessidade de inovar processos em vez de multiplicar estruturas. Tal inovação deve contemplar ações de mitigação de riscos, regras de gerenciamento para projetos, suprimentos e gestão, além da preparação da equipe.

Se, por um lado, as partes puderam alcançar seus objetivos individuais de "aprendizado", por outro lado os resultados dos empreendimentos não foram condizentes com o esperado, comprometendo o alcance dos objetivos estratégicos empresariais individuais. Entende-se que o comprometimento desses resultados está associado, em parte, à impossibilidade de se superarem algumas das dificuldades discutidas e, em outra parte, à deficiência no planejamento das parcerias e ao despreparo das empresas para a gestão dos negócios sob a nova escala verificada no período pós-parcerias.

Sob essa ótica, conclui-se que os aspectos relacionados à deficiência no planejamento tiveram maior influência no comprometimento dos resultados do que os aspectos intrínsecos às parcerias em si, tais como diferenças culturais e relacionamento entre equipes.
Ante o exposto, o presente artigo traz uma contribuição para o setor do real estate à medida que suscita reflexões sobre aspectos que podem influenciar no desempenho das parcerias e evidencia os principais pontos de fragilidade que devem ser contemplados no planejamento de futuras parcerias, visando a mitigar riscos e a elevar as possibilidades de alcance dos objetivos.

Cabe mencionar que, apesar de a pesquisa ter como foco parcerias entre empresas de diferentes regiões, entende-se que os aspectos apontados são também aplicáveis à realização de parcerias entre empresas da mesma região e, com as devidas adequações, de parcerias internacionais.

\section{Referências}

ALENCAR, C. T. Fusões e aquisições: o que mudou, o novo cenário para consolidação das grandes incorporadoras no mercado residencial. Revista Construção Mercado, São Paulo, v. 65, n. 136, p. 24-26, nov. 2012.

BARNEY, J. B.; HESTERLY, W. S. Administração estratégica e vantagem competitiva. 3. ed. São Paulo: Pearson Prentice Hall, 2011.

BARROS, B. T. (Org.). Fusões, aquisições \& parcerias. São Paulo: Atlas, 2001.

BATEMAN, T. S.; SNELL, S. A. Administração: liderança e colaboração no mundo competitivo. São Paulo: McGraw-Hill, 2007.

BRONDER, C.; PRITZI, R. Developing Strategic Alliances: a conceptual framework for successful co-operation. European Management Journal, v. 10, n. 4, p. 412-420, 1992.

BROUTHERS, K. D.; BROUTHERS, L. E.; WILKINSON, T. J. Strategic Alliances: choose your partners. Long Range Planning, v. 28, n. 3, p. $1825,1995$.

DOZ, Y. L.; HAMEL, G. A Vantagem das alianças: a arte de criar valor través de parcerias. Rio de Janeiro: Qualitymark, 2000.

FLICK, U. Uma introdução à pesquisa qualitativa. 2. ed. Porto Alegre: Bookman, 2004.

GERINGER, J. M. Strategic Determinants of Partner Selection Criteria in International Joint Ventures. Journal of International Business Studies, v. 22, n. 1, p. 41-61, 1991.

HARBISON, J. R.; PEKAR JUNIOR, P. Alianças estratégicas: quando a parceria é a alma do negócio e o caminho para o sucesso. São Paulo: Futura, 1999. 
LEWIS, J. D. Alianças estratégicas: estruturando e administrando parcerias para o aumento da lucratividade. São Paulo: Pioneira, 1992.

LIMA JUNIOR, J. R. Algumas questões do planejamento e a atual conjuntura econômica estressada. São Paulo: EPUSP, n. 16-09, abriljunho 2009. (Carta do Núcleo de Real Estate da Poli).
SOUZA, F. F. A. Análise das influências das estratégias de diversificação e dos modelos de negócios no desempenho das empresas de real estate no período de 2005 a 2010 . São Paulo, 2011. 187 f. Dissertação (Mestrado em Engenharia Civil) - Escola Politécnica, Universidade de São Paulo, São Paulo, 2011.

YIN, R. K. Estudo de caso: planejamento e métodos. 4. ed. Porto Alegre: Bookman, 2010.

\section{Cristiane Bueno de Camargo}

Departamento de Engenharia de Construção Civil, Escola Politécnica | Universidade de São Paulo | Av. Prof. Almeida Prado, Trav. 2, n. 83, Cidade Universitária | São Paulo - SP - Brasil | CEP 05508-900 | Tel.: (11) 99764-1427 | E-mail: cbc_cris@yahoo.com.br

\section{Eliane Monetti}

Departamento de Engenharia de Construção Civil, Escola Politécnica | Universidade de São Paulo | Tel.: (11) 3091-5247 | E-mail:

eliane.monetti@usp.br

Claudio Tavares de Alencar

Departamento de Engenharia de Construção Civil, Escola Politécnica | Universidade de São Paulo | Tel.: (11) 3091 -5715 |

E-mail: claudio.alencar@poli.usp.br

\section{Revista Ambiente Construído}

Associação Nacional de Tecnologia do Ambiente Construído

Av. Osvaldo Aranha, $99-3^{\circ}$ andar, Centro

Porto Alegre - RS - Brasil

CEP 90035-190

Telefone: +55 (51) 3308-4084

Fax: +55 (51) 3308-4054

www.seer.ufrgs.br/ambienteconstruido

E-mail: ambienteconstruido@ufrgs.br 